\title{
Català malparlat. Algunes propostes per a la didàctica de les desqualificacions personals a l'aula de CLE
}

\author{
Maria dels Àngels Fumadó Abad \\ Università degli Studi di Napoli L'Orientale \\ angelsfumado@hotmail.com
}

Resumen: El presente artículo tiene como primer objetivo reflexionar sobre el aprendizaje de las palabrotas y los insultos en el aula de catalán como lengua extranjera, ya que paradójicamente, a pesar de la gran cantidad de documentos publicados sobre el conocimiento que tienen y el uso que hacen los catalanoparlantes nativos de este ámbito léxico, es prácticamente nulo el material de carácter didáctico pensado para su utilización en las clases de catalán como lengua extranjera. El léxico de la ofensa personal es muy rico y variado; y tiene, además, unas características especiales, puesto que no solo es necesario aprender el significado del insulto o palabra despreciativa, sino que también es imprescindible saber utilizarlos en el contexto y el momento adecuados.

La segunda parte del artículo se propone cubrir en parte el vacío didáctico presente en este ámbito didáctico ofreciendo distintos esbozos de actividades pensadas para familiarizar a los alumnos del nivel B2 del MCER con el léxico de los insultos personales en catalán.

Palabras claveः palabrotas, insultos, catalán lengua extranjera, léxico

Abstract: This article aims to reflect on the learning of swear words and insults in the Catalan classroom. Despite the large number of reflections published on the knowledge and use of swear words by native Catalan speakers, there is practically no materials for teachers to use in the classroom. 
The lexicon of personal insults contains special features, which will be examined in the first part of the article. For example, it is not only necessary to learn the meaning of the word, but also necessary to use it in the right context at the right time.

The second part of the article proposes to partially fill the educational vacuum by offering different activities designed to familiarize B2 level students with the lexicon of swear words in Catalan.

Keywords: bad words, insults, Catalan foreign language, vocabulary 


\section{Introducció: renecs, insults i grosseries verbals a l'aula}

Tot estudiant d'una llengua estrangera ha sentit la curiositat de conèixer les paraules grolleres de la nova llengua. Els renecs i els insults tenen un no sé què de divertit. Es tracta d'un terreny quasi als marges del que és políticament correcte, que el carreguen d'atractiu, $i$ on sembla que podem comptar amb l'interès quasi immediat dels alumnes. Però no és facil, per qui els empra per primera vegada, valorar la càrrega ofensiva del renecs i els insults, saber quan i per què aquella paraula causarà l'efecte desitjat i com interpretar també les paraules ofensives que es puguin escoltar. És a dir, cal aprendre a insultar com cal aprendre a conjugar un verb, cal dominar la semàntica — no sempre els insults tenen una traducció equivalent en L1 - i la pragmàtica de l'insult, perquè les paraulotes en la boca d'un estranger perden sovint la seva força illocutiva i sonen una mica postisses, com fora de lloc, en no saber distingir, per exemple, els matisos que diferencien les diferents opcions semanticopragmàtiques que ofereix un mateix camp lèxic.

Hi ha força material publicat en paper ${ }^{1}$ i també a la xarxa sobre els improperis en català, fins i tot aplicacions per als telèfons mòbils ${ }^{2}$ o programes de la televisió dedicats als renecs $i$ als insults. Pel que fa al web hi trobem de manera abundant llistes i llistes de paraules sense donar cap tipus d'explicació sobre l'ús o el significat. En els cas dels articles, la tendència temàtica que predomina són les reflexions filològiques ${ }^{4}$ o pseudofilològiques sobre l'empobriment del repertori lèxic que se sent en la vida quotidiana respecte als renecs i els insults. Es tracta, sens dubte, de textos adreçats a persones catalanoparlants que es delectaran en la seva lectura amb un mig somriure als llavis, o que els serviran per reflexionar sobre com ens expressem els catalans en aquest àmbit de la llengua.

El Marc europeu comú de referència per a les llengües estableix que és en el nivell B2 quan l'estudiant cal que s'introdueixi en l'ús d'interjeccions, renecs, vocatius, etc., ja que és en aquest nivell on les seves produccions lingüístiques cal que sádeqüin correctament al registre i al gènere discursiu de les diferents situacions comunicatives. Així doncs, segons el Marc, cal conèixer bé una llengua abans d'insultar o de llençar-nos a dir improperis si volem que l'efecte de les nostres

1 Verdaguer, P. (1999). Diccionari de renecs i paraulotes. Perpinyà: Editorial Trabucaire.

Vidal, P. (2014). 100 insults imprescindibles. Valls: Ed. Cossetània.

2 Vegeu Insults en català pro, desenvolupat per Konfuga.es, o Insults d'en Vegeta, desenvolupat per Sasuke.

3 Vegeu, per exemple, dins de la sèrie produïda per la Televisió de Catalunya Caçadors de paraules, el capítol titulat «Som bons insultadors els catalans?» [Consultat el 16/03/2015, disponible en <https://www.youtube. com/watch?v=23EGKVT4tGA>].

4 Vegeu, per exemple, la reflexió de Puigtobella, B.: L'insult insuls [Disponible en <http://blocs.xtec.cat/jmrs/ files/2008/09/text-cl-act-7.pdf $>$ ]. 
paraules sigui eficaç i no fregui el ridícul. Tanmateix és evident que si l'estudiant es troba en una situació d'immersió lingüística acabarà sentit molts improperis pronunciats pels nadius, els aprendrà i els utilitzarà tot i que el seu nivell no correspongui a un $\mathrm{B} 2$.

Una situació ben diferent és, en canvi, la dels aprenents de català a l'estranger, els quals poc material didàctic ${ }^{5}$, per no dir gens, trobaran al seu abast. Ateses les característiques d'aquest tipus de mots (vinculats normalment amb el canal oral i el registre col+loquial), és difícil llegir mostres reals o manipulades de paraules grolleres en els manuals, o trobar-ne en els enregistraments àudio, una opció que algú podria considerar fins i tot de mal gust.

\section{Renecs $i$ insults}

Renecs $\mathrm{i}$ insults són cosins germans expressius, però no són exactament el mateix. El renec és una interjecció grossera proferida normalment en un moment de ràbia com a resposta a un fet, una circumstància, no lligada necessàriament a una altra persona, i que és producte del dolor, la sorpresa, l'admiració, la incredulitat o la indignació: ${ }^{6}$ caram, carai, collons, bòstia, merda, cagundena, redéu..., renecs molts d’ells vinculats semànticament amb el món del sexe, la religió o l’escatologia.

Quan del que es tracta és de mostrar el nostre menyspreu per l'interlocutor podem optar per fer-ho a través d'algunes estratègies de la comunicació no verbal, com ara no escoltar l'interlocutor, no mirar-lo, gesticular d'una determinada manera (que pot diferir d'una cultura a una altra); o bé optar per estratègies discursives, com pot ser carregar el discurs de paraules més aviat vulgars.

Les llengües compten, però, amb mots que tenen la funció específica d'ofendre l'altre: l'insult. El propòsit de l'insult és, en principi, ${ }^{7}$ demostrar la manca de respecte envers una altra persona, demostrar-li el nostre menyspreu i intentar ferir-la. És a dir, hi ha un atac envers «l'altre». Són mots que, a més de la seva càrrega semàntica feridora, se solen pronunciar amb ràbia i en un to molt més alt de l'habitual per augmentar-ne la seva intencionalitat violenta. De l'insult parlarem d'ara endavant.

\footnotetext{
5 Una situació semblant la trobem també en el cas de l'ensenyament de les desqualificacions personals a les classes d'espanyol com a llengua estrangera on, tot i que hi força reflexió teòrica sobre quin registre ensenyar, hi ha poc material didàctic publicat per les cases editorials del sector on hi hagi una focalització didàctica sobre el registre més collloquial, i, en absolut, no trobem enlloc cap esment a l'ofensa personal de tipus verbal.

Vegeu: Briz, A. (2002). El español coloquial en la clase de E/LE. Un recorrido a través de los textos. Madrid: Sgel.

6 Vegeu-ne, per exemple, l'ús en el relat «La nostra guerra», publicat en Pàmies S. (2006). Si menges una llimona sense fer ganyotes. Barcelona: Quaderns Crema.

7 També podem trobar, sobretot entre els joves, l'ús de l'insult amb un to afectuós, com una manera per reforçar la pertinença a un grup o els lligams d'amistat: «ei, fill de puta, com va?».
} 


\section{Lofensa verbal}

El parlant català compta amb un gran nombre de recursos lingüístics propis d'aquesta llengua per faltar al respecte a l'interlocutor: construccions fraseològiques $^{8}$, substantius, adjectius, interjeccions. Caldria exposar l'aprenent a una gran quantitat de contextos comunicatius per facilitar-li l'aprenentatge d'aquest tipus d'expressions malsonants. Però, com és lògic suposar, no podem ensenyar-les totes ni proposar-ne tampoc la multiplicitat de situacions d'ús pertinents. És evident que és necessari adoptar un criteri de selecció o, com a mínim, tenir clares quines raons ens porten a fer la tria del lèxic que presentem als estudiants.

Però, a més a més, ens topem amb una realitat sociolingüística una mica complicada. Per poc que ens hi fixem, veurem que ens trobem en un àmbit on la influència del castellà és ben evident. Pensem en mots com gilipollas, tonto, canta mañanas, d'alta freqüència d'ús a l'hora d'ofendre algú, i que tanmateix són mots manllevats del castellà, en alguns casos adaptant-los a la fonètica catalana i en d'altres, no. Què hem de fer com a professors de català? Cal fer-ne esment? Capsigrany o tonto? Què diem normalment? Carallot té avui en dia la força expressiva de gilipollas?

Aquesta és una reflexió que ja s'han fet en altres àmbits professionals, com és el cas de la televisió, on els traductors ${ }^{9} i$ els guionistes ${ }^{10}$ de les sèries s' han hagut de plantejar quin llenguatge calia utilitzar en els diàlegs entre els personatges, quin registre seguir, si acceptar o no els barbarismes. I el mateix passa a les aules. La intenció de l'insult és, com ja hem dit, demostrar una manca de respecte envers una altra persona, mostrar-li un menyspreu, fer mal verbalment, o defensar-nos davant una ofensa rebuda, per això, creiem que és necessari que l'estudiant pugui reconèixer quina és la carrega semàntica i intencional de l'insult que escolta, rep, o pronuncia.

8 Un dels recursos per ofendre que podem utilitzar consisteix a engegar algú a algun lloc o a fer alguna cosa (tipus vés a la merda, a pastar fang, a fregir espàrrecs, a fer gàrgares, a parir panteres), o els encapçalats per l'expressió em cago en, com per exemple em cago en la mare que et va parir. Vegeu, per exemple, el capítol «A parir panteres» de la sèrie de Televisió de Catalunya Català a l'atac. [Consultat el 17/03/2015, disponible en <https://www. youtube.com/watch?v=hNkiju76ui4 > ].

9 Associació Professional de Traductors i Intèrprets de Catalunya (2014). Taula rodona: El català al carrer, al bar i al llit. [Disponible en <http://traduint.wordpress.com/tag/catala-coloquial/?>] .

10 Grau i Elias, O. (2012). «El català mola si mola el que fem en català... o no». En Treballs de Sociolingüistica Catalana, núm. 22, p. 225-230. [Disponible en <http://revistes.iec.cat/index.php/TSC ISSN>].

Miriam, C. (2006). «Realitat i llenguatge en la ficció televisiva», en Actes del Tretzè Col-loqui Internacional de Llengua i Literatura Catalanes (Girona, 2003), ed. Sadurní Martí (coordinació, Publicacions de l'Abadia de Montserrat, vol. I, pp. 271-277.

David, A. (2009). «Malparits indignes» en El Periódico de Catalunya, 8 de juliol de 2009. [Disponible en <http://www.traces.uab.es/tracesbd/elperiodicodecatalunya/epc090708a.pdf > ]. 


\section{Criteris de la selecció lèxica}

En el present treball ens fixarem, doncs, en alguns del adjectius i substantius emprats per ofendre l'altre, que podem veure, llegir i sentir tant pel carrer com en els mitjans de comunicació. Deixarem de costat aquells que tenen un paral.lel en alguna de les llengües tipològicament $\mathrm{i}$ culturalment properes al català, com ara imbècil, idiota, estúpid, etc., per presentar alguns dels insults que es consideren més genuïns.

Sabem que el lèxic s'aprèn escoltant, llegint, a través d'activitats de producció, o simplement amb exercicis l'objectiu dels quals és l'aprenentatge de vocabulari. L'enfocament lèxic suggereix presentar el lèxic d'una manera organitzada i de ferho per unitats lèxiques (frases fetes, combinacions sintagmàtiques o expressions institucionalitzades), i no només a través de llistes de mots aillats, de manera que l'aprenent pugui emmagatzemar i recuperar el mot quan li calgui per expressar-se. Conèixer una unitat lèxica consisteix també a saber per què la triem i no hem optat per l'alternativa que ofereix un altre mot sinònim (inútil o cul d'olla, covard o cagabandúrries?).

A grans trets el sentit comú ens porta a classificar semànticament els insults personals en tres grans grups: a) comparació amb un animal, ja sigui pel seu aspecte físic o com per les seves capacitats mentals (ase, bèstia, capsigrany, gamarús, porc, ruc...); b) actituds o situacions personals de tipus moral, sexual, familiar, de caràcter (babau, calçasses, carallot, cornut, gamberro, llepaculs, pallús, tanoca...); i c) un tercer grup, on es volen posar en evidència les reduïdes facultats intel.lectuals d'una persona (curt de gambals, ximple, ruc...).

\section{Proposta per a la classe CLE}

Presentem una seqüència didàctica que ofereix alguns exemples de cadascun dels tres grups semàntics que hem comentat en l'apartat anterior, a partir de diferents tipologies textuals (sèries de televisió, transmissions radiofòniques, entrevistes, anuncis, cançons, literatura). Malauradament el fet que per presentar-la utilitzarem mostres reals —on per descomptat ningú no pretenia fer-ne un catàleg per als estudiants de CLE quan les va crear-complica l' organització dels mots que treballem. Per tant, en la majoria de les activitats s'hi presenten de mitjana uns deu mots amb el risc que la primera impressió pugui ser la d'unes tradicionals llistes de paraules. 


\subsection{Estructura}

La seqüència que presentem comença amb una activitat introductòria a partir de la qual l'ordre amb el qual dur a terme les altres propostes no és fixa, tot i que hi ha una gradual complexitat en la formació lèxica dels mots. En el cas en què hom decidís portar a terme totes les activitats proposades seria convenient tancar la seqüència amb una activitat que tingués com a objectiu sistematitzar els mots apresos.

\subsection{Fitxa de cadascuna de les propostes}

\subsubsection{Proposta per a l'activitat 1}

\begin{tabular}{|l|l|}
\hline Objectiu & Reflexionar sobre la pragmàtica del renec i de l'insult \\
\hline $\begin{array}{l}\text { Semàntica de la } \\
\text { desqualificació }\end{array}$ & - \\
\hline Tipologia textual & Espot publicitari \\
\hline Material & Anunci campanya publicitària Dormity.com \\
\hline Preguntes guia & $\begin{array}{l}\text { En quines situacions fem ús dels renecs normalment? Quan } \\
\text { insultem? Per què? } \\
\text { Dius paraulotes normalment en la teva llengua? I quan eres petit? } \\
\text { Et renyaven quan les deies? } \\
\text { Recordes quan has dit l'últim renec en la teva llengua materna? }\end{array}$ \\
\hline Destresa & Expressió oral \\
\hline Dinàmica & Grups 3/4 persones \\
\hline
\end{tabular}

${ }^{*}$ Consultat 30/09/2014, disponible en <https://www.youtube.com/watch?v=tszmIFQAuMY>.

\subsubsection{Proposta per a l'activitat 2}

\begin{tabular}{|l|l|}
\hline Objectiu & Presentació de manlleus del castellà \\
\hline $\begin{array}{l}\text { Semàntica de la } \\
\text { desqualificació }\end{array}$ & Desqualificació capacitats intel-lectuals \\
\hline Tipologia textual & Sèrie televisiva \\
\hline Material & $\begin{array}{l}\text { Fragments del capítol «Tinc dobles» de la sèrie Plats Bruts } \\
\text { Televisió de Catalunya }\end{array}$ \\
\hline Dinàmica & Parelles \\
\hline Destresa & Comprensió oral \\
\hline Preguntes guia & $\begin{array}{l}\text { Per què reneguen els protagonistes de la sèrie en aquest moment? } \\
\text { Què els passa? } \\
\text { Quins insults empren? } \\
\text { Els has sentit dir alguna vegada? On? }\end{array}$ \\
\hline Exponents lèxics & Tonto, gilipollas, cantamañanes \\
\hline
\end{tabular}

* Consultat 30/09/2014, disponible en <https://www.youtube.com/watch?v=6Loi6ue9k8M>. 


\subsubsection{Proposta per a l'activitat 3}

\begin{tabular}{|l|l|}
\hline Objectiu & Presentació d'insults comuns amb altres llengües \\
\hline $\begin{array}{l}\text { Semàntica de la } \\
\text { desqualificació }\end{array}$ & Desqualificació capacitats intel-lectuals \\
\hline $\begin{array}{l}\text { Tipologia } \\
\text { textual }\end{array}$ & Programa televisiu \\
\hline Material & Caràtula del programa L'imbècil del trimestre de 8tv \\
\hline Dinàmica & Parelles \\
\hline Destresa & Comprensió oral \\
\hline Preguntes guia & $\begin{array}{l}\text { Has observat que alguns insults quasi coincideixen en algunes } \\
\text { llengües? En recordes algun? } \\
\text { Quin déu ser el motiu d'aquesta coincidència? }\end{array}$ \\
\hline $\begin{array}{l}\text { Exponents } \\
\text { lèxics }\end{array}$ & Imbècil, idiota, estúpid \\
\hline
\end{tabular}

\subsubsection{Proposta per a l'activitat 4}

\begin{tabular}{|c|c|}
\hline Objectiu & Presentació de lèxic \\
\hline $\begin{array}{l}\text { Semàntica de la } \\
\text { desqualificació }\end{array}$ & $\begin{array}{l}\text { Desqualificació capacitats intel-lectuals, actituds ètiques, compor- } \\
\text { tament i caràcter }\end{array}$ \\
\hline $\begin{array}{l}\text { Tipologia } \\
\text { textual }\end{array}$ & Espot publicitari \\
\hline Material & $\begin{array}{l}\text { Paròdia d'espot del Banc de Sabadell realitzada pel programa } \\
\text { Opera en Texans de Televisió de Catalunya dedicat a Le Grande } \\
\text { Macabre }\end{array}$ \\
\hline Dinàmica & Individual \\
\hline Activitat lèxica & $\begin{array}{l}\text { Escriure un insult que comenci amb cadascuna de les lletres de } \\
\text { l'alfabet. } \\
\text { Entendre el significat del mots a partir d'una sèrie d'illlustracions. } \\
\text { Completar un exercici introduint la desqualificació personal més } \\
\text { adequada a cada frase. }\end{array}$ \\
\hline $\begin{array}{l}\text { Exponents } \\
\text { lèxics }\end{array}$ & $\begin{array}{l}\text { Animal, barjaula, capsigrany, dropo, enze, fatxenda, galifardeu, } \\
\text { hortera, impresentable, Judes, kamikaze, llepaculs, mamarratxo, negat, } \\
\text { obtús, pòtol, que maco, repel+lent, sapastre, tita freda, usurer, viciós, } \\
\text { wagnerià, xitxarel.lo, yupi, zombi }\end{array}$ \\
\hline
\end{tabular}

* Consultat 30/10/2014, disponible en <https://www.youtube.com/watch?v=iobpOXCMEXI>. 


\subsubsection{Proposta per a l'activitat 5}

\begin{tabular}{|l|l|}
\hline Objectiu & Treballar la sinonímia i la pragmàtica de l'insult \\
\hline $\begin{array}{l}\text { Semàntica de la } \\
\text { desqualificació }\end{array}$ & Desqualificació ètica \\
\hline Tipologia textual & Poema (sinonímia) \\
\hline Material & $\begin{array}{l}\text { Poema d'en Gerard Vergés, «Abundància de sinònims» dins Lliri } \\
\text { entre cards (1988), musicat per Enric Panisello Salvador }\end{array}$ \\
\hline Dinàmica & Individual \\
\hline Destresa & Comprensió lectora* \\
\hline Preguntes guia & $\begin{array}{l}\text { Quants insults apareixen en aquests poema? Com els podem agru- } \\
\text { par? A qui van referits? Als homes o a les dones? }\end{array}$ \\
\hline Exponents lèxics & $\begin{array}{l}\text { bagassa, bardaixa, barjaula, barragana, berganta, donota, galiota, } \\
\text { betaira, marcolfa, marfanta, meretriu, meuca, prostituta, putana }\end{array}$ \\
\hline
\end{tabular}

* Es tracta un mot que pot tenir molts significats depenent de les altres unitats amb què es combina. Per a la polisèmia del mot puta, podeu consultar: La polisèmia de la paraula 'puta' amb el filòleg Pau Vidal. [Disponible en <http://www.ara.cat/arabassas/el_focus/polisemia-paraula-filoleg-Pau-Vidal_3_1129717035.html>].

És curiós també en aquest sentit la publicació del llibre: Martell, J. (2014). Les putes receptes de la iaia. Barcelona: Editorial la Galera.

\subsubsection{Proposta per a l'activitat 6}

\begin{tabular}{|c|c|}
\hline Objectiu & Comparacions despectives \\
\hline $\begin{array}{l}\text { Semàntica de la } \\
\text { desqualificació }\end{array}$ & $\begin{array}{l}\text { Desqualificació capacitats intel-lectuals, actituds ètiques, compor- } \\
\text { tament i caràcter }\end{array}$ \\
\hline Tipologia textual & Fragment pel-lícula \\
\hline Material & $\begin{array}{l}\text { Fragment (minuts del } 35 \text { al 38) de Pa negre (2010) d'Agustí } \\
\text { Villaronga, basada en la novel.la homònima d'Emili Teixidor } \\
\text { (2003) }\end{array}$ \\
\hline Dinàmica & Individual i en parella \\
\hline Destresa & Comprensió oral \\
\hline Preguntes guia & $\begin{array}{l}\text { Per què s'insulten els nens? Qui insulta a qui? Reconeixes el nom } \\
\text { d'algun animal? }\end{array}$ \\
\hline Activitat lèxica & Deduir la combinació correcta dels mots \\
\hline Exponents lèxics & $\begin{array}{l}\text { més curt que una cua de conill, més pobre que una rata, més tossut } \\
\text { que una mula, més sec que els peus d'un sant, més beneit que una } \\
\text { espardenya, més lent que una processó de coixos, més pesat que una } \\
\text { vaca amb braços }\end{array}$ \\
\hline
\end{tabular}




\subsubsection{Proposta per a l'activitat 7}

\begin{tabular}{|l|l|}
\hline Objectiu & Unitats fraseològiques i mots compostos \\
\hline $\begin{array}{l}\text { Semàntica de la } \\
\text { desqualificació }\end{array}$ & $\begin{array}{l}\text { Desqualificació capacitats intel-lectuals, actituds ètiques, } \\
\text { comportament i caràcter }\end{array}$ \\
\hline Tipologia textual & Text cançó \\
\hline Material & Estanislau Verdetः Per fer país insultem en català* \\
\hline Dinàmica & Individual i en parella \\
\hline Destresa & Comprensió oral \\
\hline Preguntes guia & $\begin{array}{l}\text { Hi ha insults a la teva llengua format per la combinació de } \\
\text { diversos mots? Pots explicar-ne el sentit als teus companys? }\end{array}$ \\
\hline Activitat lèxica & $\begin{array}{l}\text { Anàlisi del elements que componen aquestes desqualificacions. } \\
\text { Fer una hipòtesi del significat. }\end{array}$ \\
\hline Exponents lèxics & $\begin{array}{l}\text { cagadubtes, el cul d'en Jaumet, primmirat, pelacanyes, cap de trons, } \\
\text { cap de pardals, pixa-reixes, cul d’olla, figaflor, poca-traça, cagacalces, } \\
\text { camacurt, perepunyetes }\end{array}$ \\
\hline
\end{tabular}

* Disponible en <http://www.viasona.cat/grup/estanislau-verdet/un-que-de-tan-llest-es-tonto-i-un-que-detan-tonto-es-llest/per-fer-pais-insultem-en-catala $>$.

\subsubsection{Proposta per a l'activitat 8}

\begin{tabular}{|l|l|}
\hline Objectiu & Sinònims \\
\hline $\begin{array}{l}\text { Semàntica de la } \\
\text { desqualificació }\end{array}$ & $\begin{array}{l}\text { Desqualificació capacitats intel-lectuals, actituds ètiques, } \\
\text { comportament i caràcter }\end{array}$ \\
\hline Tipologia textual & Sèrie de dibuixos animats \\
\hline Material & Fases del personatge Vegeta de Bola de Drac $Z^{*}$ \\
\hline Dinàmica & En parelles \\
\hline Activitat lèxica & $\begin{array}{l}\text { Formular hipòtesis sobre el significat de les qualificacions a partir } \\
\text { del context on són dites. }\end{array}$ \\
\hline Exponents lèxics & $\begin{array}{l}\text { Patata (sapastre, maldestre), merda (poruc, un no res), dròpol } \\
\text { (gandul, mandrós), pallasso (ridicul), curt de gambals (babau), ruc } \\
\text { (ximple), ase (gamarús), baliga-balaga (poca-solta) }\end{array}$ \\
\hline
\end{tabular}

* Bola de Drac és una sèrie d'animació japonesa, creada originalment per Akira Toriyama, Editorial Shueisha, Tokio, 1984-1995. Primer va aparèixer en format de còmic. [Consultat el 9/9/2014, disponible en <http:// www.youtube.com/watch?v=zhPhmMm18zA $>\mathrm{i}<\mathrm{http}$ : / www.youtube.com/watch? $=z \mathrm{hPhmMm} 18 \mathrm{zA}>$ ].

\section{Conclusions}

No és una tasca facil portar el lèxic de les desqualificacions personals a l'aula de català com a llengua estrangera. En primer lloc, perquè és un dels àmbits lèxics on es fa més palès un dels majors problemes sociolingüístics dels territoris de 
parla catalana: la influència de la llengua castellana. Per tant, cal plantejar-se si ensenyar o no els mots que és molt probable que els estudiants escoltin fora de l'aula quan es trobin en un procés d'immersió lingüística, però també en diferents programes transmesos per la televisió, en la literatura o en la música.

En segon lloc, tal com moltes publicacions sestan encarregant de difondre, el català presenta una gran riquesa en aquest àmbit lèxic, tant pel que fa als significat dels mots, com a la seva formació i estructura lèxica. Per tant, si l'objectiu no és confondre o avorrir amb un excés de material els alumnes, cal fer una tria encertada dels mots que presentarem i treballarem a classe.

En tercer lloc, roman sempre la dificultat d'ensenyar de manera adient l'ús de l'insult en el moment i el lloc adequats, és a dir, cal ensenyar també a dominar la pragmàtica de la desqualificació, fet que pot resultar complicat.

Per acabar, creiem que el més adient seria anar introduint les propostes que hem presentat no com a seqüència didàctica, sinó inserides dins d'unitats on es tractin altres temàtiques. Per exemple, podem tornar en el nivell B2 a la descripció física o de caràcter de les persones afegint-hi els adjectius i expressions desqualificadores que no s'han vist en els cursos inferiors i que ara sí que es poden introduir. $\mathrm{O}$ el mateix es pot fer en tractar una temàtica relacionada amb el món dels animals.

En qualsevol cas, queda encara per endavant molta feina per fer per tal de poder disposar de més material didàctic amb el qual treballar aquest tipus de lèxic a les aules. El món dels renecs i els insults és viu i ric, i per què no, útil.

\section{Bibliografia}

Austin, J. (1982). Cómo hacer cosas con palabras: Palabras y acciones. Barcelona: Paidós.

Avellaneda, J. (2006). Viatge a l'origen dels insults. Barcelona: Ara Llibres SCCL.

Briz, A. (2002). El español coloquial en la clase de E/LE. Un recorrido a través de los textos. Madrid: SGEL.

Buxarrais, M.R. i Tey, A. (2007). «El llenguatge televisiu groller com a indicador ètic de la cultura d'una societat». Quaderns del CAC, Barcelona, vol. 28: 79-86. <http://www.youtube.com/watch?v=1OS0ONWWM50\& feature $=$ related $>$.

Caçadors de paraules: «Som bons insultadors, els catalans?» Producció TVC, 2007. [<http://www.edu3.cat/Edu3tv/Fitxa?p_id=23245>]

Castellanos, C. (2001). «Malparlar bé». Llengua Nacional, vol. 5: 36-39. 
Espinal i Farré, M.T. (2004). Diccionari de sinònims de frases fetes. Barcelona / València: Universitat Autònoma de Barcelona. Publicacions de la Universitat de València. Publicacions de l’Abadia de Montserrat.

Garrido Rodríguez, M. C. (2001). «¿Qué español coloquial enseñar en las clases de E/LE?». En: Martín Zorraquino, Ma A. y Díez Pelegrín, C. (eds.) (2001). ¿Qué Español Enseñar? Norma y Variación Lingüísticas en la Enseñanza del Español a Extranjeros (Actas del XI Congreso Internacional de ASELE, Universidad de Zaragoza, los días 13-16 de septiembre de 2000). Universidad de Zaragoza: 365-373.

Higueras García, M. (2009). «Aprender y enseñar léxico». Enः N. Sans i MiQuel, L. (coord.). Monográficos marcoELE, Didáctica del español como lengua extranjera. Madrid: Expolingua, vol. 9: 111-126.

- (2004). «Claves prácticas para la enseñanza del léxico». CARABELA, La enseñanza del léxico en español como segunda lengua/lengua extranjera, vol. 56: $5-25$.

Martell, J. (2014). Les putes receptes de la iaia. Barcelona: Editorial la Galera.

Puigtobella, B. (2014). L'insult insuls. [<http://blocs.xtec.cat/jmrs/files/2008/09/text-cl-act-7.pdf $>$ ]

- (2014). Pau Vidal contra l'insult insuls. [<http://www.nuvol.com/noticies/ pau-vidal-contra-linsult-insuls $>$ ]

Salvanyà, J. (2009). Diccionari del català col.loquial. Dubtes davant del micròfon. Barcelona: Enciclopèdia Catalana.

Santos, C. (2011). Insultos y expresiones malsonantes en la clase de ELE. Revista electrónica de didáctica del español lengua extranjera (redELE). [<http:// www.educacion.gob.es/dctm/redele/Material-RedEle/Revista/2011_23>]

Soler-Espiauba, D. (1998). «¿Existe una didáctica de las «malas palabras»? ¿Son, además de malas, «peligrosas»?»+ En; Jiménez, T+; Losada, M.C y Márquez, J.F (eds) (1998), Español como Lengua Extranjera: Enfoque Comunicativo y Gramática (Actas del XI Congreso Internacional de ASELE, los días 23-26 de septiembre de 1998). Universidad de Santiago de Compostela: 269-278.

Ventalló, J. (2011). Llamp de llamp de rellamp de contra-rellamp. Barcelona: A contra vent editors.

Verdaguer, P. (1999). Diccionari de renecs i paraulotes. Perpinyà: Editorial Trabucaire.

Vidal, P. (2014). 100 insults imprescindibles. Valls: Ed. Cossetània. 